\title{
Application of transient electromagnetic method to detect near surface loess layer in Western China
}

\author{
Zuzhi $\mathrm{Hu}$, Xiangyun $\mathrm{Hu}$ \\ Institute of Geophysics and Geomatics \\ China University of Geosciences(Wuhan) \\ Wuhan, Hubei
}

\author{
Zhanxiang He, Zhongcheng Jiang, Dechun Li, Yunjian \\ Yang, Shujiang Yang \\ BGP, CNPC \\ Zhuozhou, Hebei
}

\begin{abstract}
The topography of the foreland thrust zone in western China is complicated. In those areas, the mountains are steep and the loess layer is thick, which cause the quality of seismic data in these areas is poor. With continuous research in recent years, the quality of seismic data has been improved to some extent. However, it is still difficult to identify the structural traps and build accurate velocity model. It has received a better exploration results on the recognition of loess characteristics and distribution with transient electromagnetic method in the foreland thrust zone. In this paper, the achievement of detecting near surface loess layer in western China using transient electromagnetic exploration is shown. It can be combined with micro-logging to provide the basis for building shallow velocity model for the static correction of the seismic data
\end{abstract}

Keywords-transient electromagnetic; loess layer; shallow velocity model

\section{INTRODUCTION}

The underground and surface conditions of $\mathrm{BD}$ area, located in western China, are complicated. Its surface covers with high-steep mountain and thick loess layer, which leads to the receiving energy of far trace is very weak and the serious adoption attenuation of seismic wave. It is difficult to determine the top boundary of the high velocity layer and build the surface velocity model. Due to these factors, the quality of seismic data is poor, which seriously restricts the further exploration. Considering the high resolution of shallow electrical layer, the oil company deployed the transient electromagnetic (TEM) survey in the DK fractural structure area to study the distribution and the variation trend of the loess layer, which can be used to build the shallow velocity model for seismic static correction.

\section{METHOD}

The TEM method is an important branch method of electromagnetic exploration. The TEM utilizes ground wire or ungrounded circuit wire to transmit a pulse electromagnetic field. It uses a square-shaped cable loop to excite current, and record the secondary field at the center of the loop. The significant advantage of this method is that only secondary field is received without background of the primary field. It can be observed in near field even zero offset to reduce the volume effect and side effect.

The transmitter of TEM can be line source or magnetic

This research is funded by the National Major Projects (2016ZX05019008-001). source. Generally the vertical magnetic field is received; other components of electromagnetic field can also be received. Among several transient electromagnetic configures, because the in-loop configure adopts loop-source and receives secondary vertical magnetic field in the center of the loop, this configure has good coupling effect between the receiver loop and the target. It has some important advantages, such as high resolution, no static shift effect, simple shape of anomaly curve, small volume effect and side effect. Therefore, the in-loop configure with loop side $200 \mathrm{~m}$ is chosen. The direction of loop side is north-south and east-west trend.

At present, there are three types of software available for the inversion of TEM data: EMIGMA, IX1D and LOOPTEM (BGP developed). We did the trial inversion with the three programs individually, and the three show good consistency each other in general, while the data inverted with the last one provides more details. We therefore used LOOPTEM to process the TEM data.

\section{APPLICATION}

The loess layer in $\mathrm{BD}$ area often distributes on the top of the Quaternary. According to the survey of the shallow logging data, it can be divided in two sets: one is sub-sand-soil, a set of Quaternary aeolian sediment, covered on the surface. The main components are the silty fine clastic particles, which are porous and dusty. The other is sub-clay which is under the sub-sandsoil layer, also a set of Quaternary sediment, the main components of which are fine argillaceous clastic particles. This set of the loess layer is relatively tight with certain compaction.

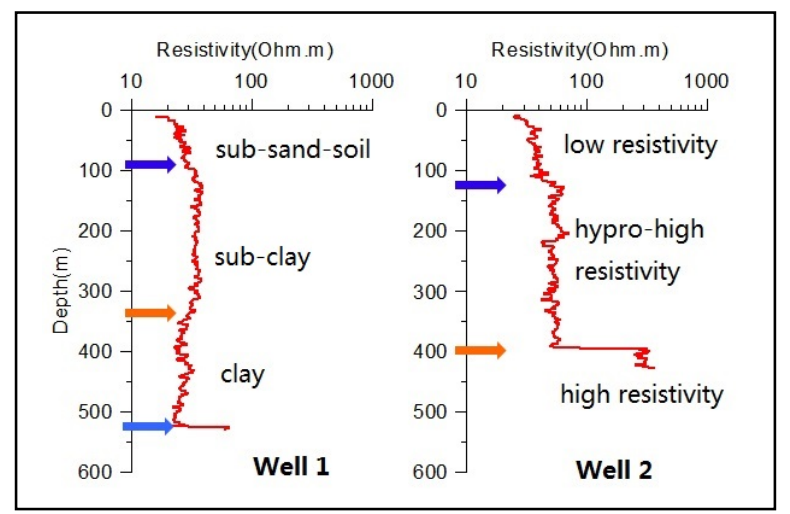


Fig. 1. Resistivity curves and lithology of two shallow loggings in southern west of BD area.

According to analysis the resistivity curves of two shallow logging data in southwest of BD area (Fig. 1), the resistivity of the surface sub-sand-soil layer shows a characteristics of low resistivity with 6-10 $\Omega \mathrm{m}$; the underlying layers of sub-clay and clay show a characteristics of hypro-high resistivity with $10-80$ $\Omega \mathrm{m}$.

The Fig. 2 shows the resistivity section inverted by TEM data through well BD1 and well BD3 in BD area. Through the calibration of wells, the resistivity of the surface sub-sand-soil layer shows a characteristic of low resistivity with 1-4 $\Omega \mathrm{m}$; the underlying layers of sub-clay and clay show a characteristic of hypro-high resistivity with $4-10 \Omega \mathrm{m}$.

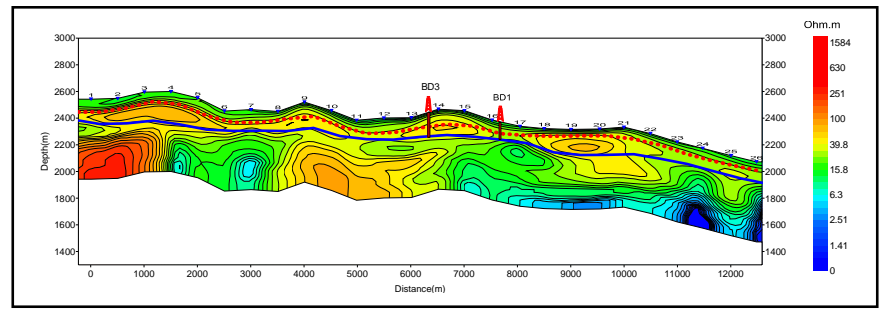

Fig. 2. Resistivity section inverted by TEM data through well BD1 and BD3.

According to the loess layer interpretation by tracking calibration in the DK area, the thickness of loess layer is mapping. Fig. 3 shows the map of loess layer thickness predicted by the TEM data. It is indicated that the loess layer in the area mainly distributes in the west of this area, and the most thickness is about $260 \mathrm{~m}$.

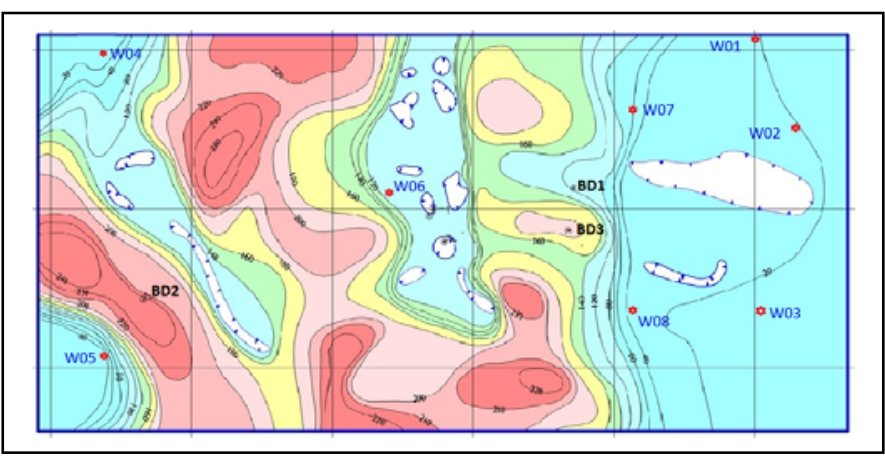

Fig. 3. Map of loess thickness predicted by TEM data.

The thickness of the center in west area can be divided into two basic bands, which has a great correlation with the terrain. The trend of the thickness center is NW, which is consistent with that of loess hill. In the valley scoured by the river between loess hills, the thickness of loess layer turn to thin. Near well BD1 in the mid-east area, it can be separated to four NWW trending thickness centers from south to north, which is thinner than that of well BD2. Its thickness can reach 180$200 \mathrm{~m}$. In the east of the area, the thickness of loess layer is thin, generally less than $50 \mathrm{~m}$.
Following the TEM exploration, the oil company has drilled dozens of micro-logs to verify the prediction. Table 1 lists the comparison of the loess layer thickness by TEM and the drilled data on 8 wells. From TABLE 1, it can be seen that among the 8 wells, the thickness of absolute error is about $-5 \mathrm{~m}$ to $4.5 \mathrm{~m}$ between the predicting thickness calibrated by well BD1 and BD3 and actual thickness, which is meet the demand of the precision for further seismic exploration.

TABLE I. COMPARISON OF THE LOESS LAYER THICKNESS BY TEM and THE DRILLED DATA

\begin{tabular}{|c|c|c|c|}
\hline $\begin{array}{c}\text { Microlog } \\
\text { name }\end{array}$ & $\begin{array}{c}\text { Thickness of } \\
\text { predicted } \\
\text { (m) }\end{array}$ & $\begin{array}{c}\text { Thickness of } \\
\text { drilled (m) }\end{array}$ & $\begin{array}{c}\text { Differenc } \\
\text { e (m) }\end{array}$ \\
\hline W01 & 26 & 30.5 & 4.5 \\
\hline W02 & 22 & 21.2 & -0.8 \\
\hline W03 & 14 & 10.1 & -3.9 \\
\hline W04 & 18 & 19.1 & 1.1 \\
\hline W05 & 42 & 37 & -5 \\
\hline W06 & 19 & 16.5 & -2.5 \\
\hline W07 & 62 & 65.7 & 3.7 \\
\hline W08 & 36 & 38.8 & 2.8 \\
\hline
\end{tabular}

\section{CONCLUSIONS}

We successfully apply the TEM to solve the thickness distribution of loess layer in the foreland thrust zone. The difference of thickness between predicted by TEM and the micro-logging data is less than $5 \mathrm{~m}$, which is very important for the investigation of the shallow low velocity zone caused by loess layer and the water table in seismic survey for complicated topography area. The predicted result of loess layer by TEM can be combined with micro-logging data to provide the basis for building the shallow velocity model for seismic exploration design and seismic data static correction.

\section{REFERENCES}

[1] L. Pellerin and G. W. Hohmann, "Transient electromagnetic inversion: A remedy for magnetotelluric static shifts," Geophysics, vol. 55, no 9, pp. $1242-1250,1990$.

[2] A. P. Raiche, D. L. B. Jupp, H. Rutter and K. Vozoff, "The joint use of coincident loop transient electromagnetic and Schlumberger sounding to resolve layered structures," Geophysics, vol 50, no 10, pp. 1618-1627, 1985.

[3] A. Swidinsky and M. Nabighian, "On smoke rings produced by a loop buried in a conductive half-space," Geophysics, vol 80, no 4,pp. E225E236, 2015.

[4] G. Q. Xue, J. P. Song and S. Yan, " Detecting the cavity with one of non-seismic methods," The Leading Edge, vol 23, pp. 694-695, 2004.

[5] G. Q. Xue, N. N. Zhou, W. Y. Chen, H. Li and S. Yan, "Research on the application of a 3-m transmitter loop for TEM survey in mountainous areas," Journal of Environmental and Engineering Geophysics, vol 19, no 1, pp. 3-12, 2014.

[6] Y. J. Yang, X. B. Wang and Z. X. He, "1D inversion of transient electromagnetic data in consideration of ramp time effect," Geophysical and Geochemical Exploration, vol 29, no 3, pp. 232-234, 2005. 